\title{
Evaluation of Climate Change Adaptation in the Energy Sector in China via a Composite Index
}

\author{
Yubing SHANG * and Rong KANG \\ Northwest University, Xi'an, Shaanxi, China; 732225257@qq.com; 1057816418@qq.com \\ * Correspondence: 732225257@qq.com
}

\begin{abstract}
Climate change will affect the energy sector and the energy sector must take measures to adapt to future climate conditions. Before taking measures, it is necessary to understand the current adaptation of energy sector to climate change. Therefore, this paper is to assess the adaptation of energy sector in China to climate change in 2000-2017 through a comprehensive index. In order to establish a comprehensive index, three sub-indexes are determined first, and the climate change adaptation index (CCAI) is finally obtained through standardization treatment, weight determination and index summary. The results of CCAI show the energy sector in China put forward a reactive adaptation scheme in 2000-2010, which has a high system vulnerability. After 2010 , there was an anticipatory adaptation scenario in which vulnerability was average. Although a short leap of planned adaptation was achieved in 2011 and 2013, which greatly reduced the vulnerability of the system, the state is not stable. As a whole, the energy sector in China has made some progress from the reactive adaptation scenario wherein the vulnerability was high to an anticipatory adaptation scenario wherein the vulnerability was average, indicating that the foundations for this sector to build a planned adaptation are currently being laid.
\end{abstract}

Keywords: the energy sector in China; adaptation to climate change; composite index; system vulnerability; climate change adaptation index (CCAI)

JEL Classification: Q49; Q54

\section{Introduction}

Climate change is a major global problem that the international community is generally concerned about. Human beings are experiencing global warming, frequent extreme climate events, increasing disaster intensity and other climate change issues. Climate change is becoming a slow-onset disaster, which has a serious impact on human society, and its potential loss puts forward the requirements of adaptation to climate change to all countries in the world. The issue of global climate change is not only an environmental issue, but also an energy issue. Optimizing energy structure, improving energy efficiency, developing and applying low-carbon technology, changing ideas and enhancing awareness of low-carbon consumption are considered to be important ways to deal with climate change globally. The World Energy Council reports that sea-level rise, extreme weather, drought and flood caused by climate change can wreak havoc on the global energy system. At the same time, energy facilities such as power plants and distribution networks are likely to be affected by accelerated global warming. Christoph Frei, the secretary-general of the World Energy Council, added: "climate change is bound to affect the energy sector. We need a strong and transparent policy framework to unlock the long-term investments we desperately need for the future."

So there is no doubt that the energy sector should take adaptive measures to deal with climate change and avoid serious problems, such as protecting power plants from the threat of water shortages and building power grid restoration systems. The energy sector is a key factor in climate change, as it not only generates GHG, but is also affected by climate change and has to adapt to future climate conditions.

However, according to the current research on the energy sector in China in the context of climate change, it is generally divided into two categories. One is the study of energy law under 
climate change. For example, in 2011, Chen Jue focused on the relationship between energy development and climate change, and discussed the necessity and significance of providing legal protection for China to deal with climate change in energy legislation. Focusing on the Renewable Energy Law, Ke Jian (2015) analyzed and reviewed China's renewable energy legislation, and put forward many concrete policies and suggestions. In 2016, Wang Juan studied the development and law of renewable energy in the context of climate change. In the course of exploring the relevant systems of China's energy law, Liu Congcong (2017) found that optimizing the energy law system from the aspects of energy legal system, energy planning system and ecological compensation system can enable China to obtain certain advantages in the field of international climate negotiations In 2018, Zhai Ruiyan expounded the legal countermeasures or suggestions to deal with climate change from the point of view of energy law. The second is to assess the climate risks of energy in China. For example, Ding Ding(et al.2015) preliminarily analyzed the climate risk and its characteristics of the energy sector, tried to put forward the framework of climate risk assessment and management system of energy sector, and put forward corresponding suggestions on how to assess and manage the climate risk of energy sector and industry. Based on the influence factors of renewable energy development, Wang Bing (2016) discussed the vulnerability of climate change, quota system and social cognitive risk in its natural risk, and put forward relevant policy suggestions for climate risk aversion of renewable energy in China in the future. Yang Lizhi (et al.2016) studied the marine environment response in the context of climate change and its possible impact and potential risks on the safety of offshore energy channels to provide decision-making reference for addressing climate change and ensuring the safety of energy channels in China.

At present, China has become the largest energy producer and consumer in the world. All aspects of energy production and utilization are potentially affected by climate change, and even face severe climate challenges. Therefore, while carrying out climate risk assessment and formulating corresponding risk management strategies in the energy sector, China should also understand the current climate change adaptation of the energy sector in China. As far as the existing studies are concerned, there is almost no study on climate change adaptation in the energy sector. The energy sector is one of the sectors most vulnerable to climate change, and its role is far-reaching, which means that the energy sector must take measures to adapt to future climate conditions. Therefore, this paper uses a comprehensive index to evaluate the current adaptation of China's energy sector to climate change, which is not only the first time to directly reflect the adaptability of China's energy sector to climate change through quantitative comprehensive indicators, but also helps decision makers to look at the reality of the energy sector in a more comprehensive perspective, which is conducive to the decision-making in the future. This paper can initially meet the demand for tools, which provide more certainty for assessing the progress of the energy sector in adapting to climate change.

\section{Methodology}

In order to be able to evaluate the progress of the energy sector in adapting to climate change based on the comprehensive index, this paper is based on the following research steps: conceptual definition, indicator selection, indicator standardization, weighting of indicators, and aggregation of indicators, and finally a comprehensive indicator.

\subsection{Definition of the conceptual}

Adaptation is the adjustment of natural or human systems to actual or anticipated climate stimuli and their effects, thereby mitigating harm or taking advantage of beneficial opportunities (IPCC 2007). Generally speaking, adaptation can be divided into reactive adaptation and active adaptation. Reactive adaptation refers to the measures taken to deal with climate change after natural events, while the active adaptation includes expected adaptation and planned adaptation, which refers to the adaptation that occurs before the climate impact is observed and requires conscious and

planned intervention to reduce its vulnerability(Beermann 2011; Busch 2011). In addition, according to IPCC $(2001,2007,2014)$, vulnerability refers to the tendency of human systems to be adversely 
affected. According to the IPCC, the concept of vulnerability includes sensitivity or susceptibility to damage, or lack of capacity to respond and adapt to climate impacts. Therefore, vulnerability is understood as the opposite relationship with adaptive ability, that is, the greater the adaptive ability, the smaller the vulnerability of the system.

\subsection{Indicator selection}

According to the availability and correlation of the index, this paper selects five variables (three kinds of sub-indicators) as the object of analysis. The first category is reactive adaptation index, in which thermal energy is used instead of hydraulic energy for evaluation. The second category is the anticipatory adaptation index, measured by the gap between the total power production and the total power consumption. The third category is the planned adaptation index, in which three variables should be taken into account, including climate assistance funds for the energy sector in the area of adaptation, energy law in the context of climate change, and percentage of total installed renewable energy power generation. Based on the previously referenced criteria, Table 1 lists the selected indicators. For the index of "energy law in the context of climate change", this paper combs the relevant legal documents and divides them into different levels (see Table 2). Through the above method, the related index data of five variables under different adaptation types are obtained, and the original index data are summarized in Table 3.

Table 1. Index selection based on adaptation type.

\begin{tabular}{|c|c|}
\hline Types of adaptation & Indicators selected based on the type of adaptation \\
\hline Reactive adaptation & $\mathrm{X} 1$ :Thermal Generation /Total Generation（Billions of kWh） \\
\hline Anticipatory adaptation & $\begin{array}{l}\mathrm{X} 2 \text { :Total power production - Total power energy consumption } \\
\text { (Billions of } \mathrm{kWh})\end{array}$ \\
\hline \multirow{3}{*}{ Planned adaptation } & $\begin{array}{l}\text { X3 :Climate assistance funds for the energy sector in the area of } \\
\text { adaptation/All climate assistance funds received in the adaptation } \\
\text { area (USD thousand, constant } 2016 \text { prices) }\end{array}$ \\
\hline & $\mathrm{X} 4$ :The legal level of energy in the context of climate change \\
\hline & $\begin{array}{l}\text { X5 :Total installed renewable energy power generation/Total } \\
\text { installed power generation (Ten thousand kilowatts) }\end{array}$ \\
\hline
\end{tabular}

Table 2. Hierarchical classification of indicators for "energy law in the context of climate change"

\begin{tabular}{lc}
\hline Rating & Meaning \\
\hline 1 & There is no specialized law on renewable energy. \\
2 & $\begin{array}{c}\text { There are specialized laws on renewable energy, but there are no corresponding } \\
\text { administrative regulations. (but corresponding government rules, local regulations, } \\
\text { etc.) }\end{array}$ \\
& $\begin{array}{c}\text { There are specialized laws on renewable energy, and there are corresponding } \\
\text { administrative regulations, etc. }\end{array}$ \\
\hline
\end{tabular}

Table 3. Raw indicator data for different types of adaptation

\begin{tabular}{cccccc}
\hline Years & $\begin{array}{c}\text { Reactive } \\
\text { adaptation }\end{array}$ & $\begin{array}{c}\text { Anticipatory } \\
\text { adaptation }\end{array}$ & \multicolumn{3}{c}{ Planned adaptation } \\
\hline & X1 & X2 & X3 & X4 & X5 \\
2000 & 0.8219 & 83.6 & 0 & 1 & 0.249 \\
2001 & 0.7947 & 84.5 & 0 & 1 & 0.246 \\
2002 & 0.8025 & 74.5 & 0 & 1 & 0.243 \\
2003 & 0.8272 & 74.2 & 0 & 1 & 0.244 \\
\hline
\end{tabular}




\begin{tabular}{lccccc}
\hline 2004 & 0.815 & 61.7 & 0 & 1 & 0.24 \\
2005 & 0.8188 & 62.3 & 0 & 2 & 0.229 \\
2006 & 0.8269 & 69.3 & 0 & 2 & 0.212 \\
2007 & 0.8319 & 103.7 & 0 & 2 & 0.212 \\
2008 & 0.7809 & 127.4 & 0 & 2 & 0.228 \\
2009 & 0.803 & 114.3 & 0 & 2 & 0.245 \\
2010 & 0.792 & 137.1 & 0 & 2 & 0.254 \\
2011 & 0.8134 & 129.3 & 0.032980738 & 2 & 0.265 \\
2012 & 0.7805 & 112.9 & 0.020435864 & 2 & 0.28 \\
2013 & 0.7819 & 113 & 0.028920323 & 3 & 0.297 \\
2014 & 0.7594 & 112.1 & 0.01874509 & 3 & 0.311 \\
2015 & 0.7368 & 125.7 & $9.65763 \mathrm{E}-05$ & 3 & 0.323 \\
2016 & 0.7235 & 127.8 & 0.016474977 & 3 & 0.346 \\
2017 & 0.7199 & 130.4 & 0.001968504 & 3 & 0.366 \\
\hline
\end{tabular}

\subsection{Indicator standardization}

Because the variables are expressed in different units of measurement, in order to convert them into an index, according to the relationship between the indicators and adaptation to climate change, the deviation standardization method is used to convert them to obtain standardized indicators.

Then, if the relationship is positive, the formula used is

$$
X_{\mathrm{i}}^{\prime}=\frac{X_{i}-m_{i}}{M_{i}-m_{i}}
$$

However, when the relationship is negative, the equation used is

$$
X_{\mathrm{i}}^{\prime}=\frac{M_{i}-X_{i}}{M_{i}-m_{i}}
$$

where $X_{i}$ is the parameter value of indicator for a given period, $m$ is the minimum value of the variable for a given period, and $M$ is the maximum value. Standardized by formulas (1) and (2), the values of each variable fluctuate between 0 and 1 .

\subsection{Weighting of indicators}

After standardizing the data, the weight of each variable is determined according to the entropy method, and the following index weights are obtained: Reactive adaptation $\left(\mathrm{W}_{1}\right)=7.01 \%$, Anticipatory adaptation $\left(\mathrm{W}_{2}\right)=10.6 \%$, Planned adaptation $\left(\mathrm{W}_{3}\right)=82.39 \%$. (Among them, the proportion of climate assistance funds to the energy sector in the field of adaptation is $52.32 \%$, the proportion of the legal level of energy to adapt to climate change is $16.08 \%$, and the proportion of the total installed capacity of renewable energy is $13.99 \%$.)

\subsection{Aggregation of indicators}

When each kind of data is standardized, the data of each variable are obtained. There are three variables under the planning adaptation index. If we want to get the planning adaptation index, we must summarize the data. Therefore, according to the proportion of the three variables in the planned adaptation, the planned adaptation index was obtained by weighted summary of $\mathrm{X}_{3^{\prime}} 、 \mathrm{X}_{4} 、 \mathrm{X}^{\prime}{ }^{\prime}$. 


\subsection{Climate change adaptation index (CCAI)}

In order to obtain a comprehensive index for each year, the indices of each variable are multiplied by their respective weights, then the indicators are summarized and the climate change adaptation index (CCAI) is finally calculated. The index calculation formula would be the following:

$$
C C A I=\sum_{i=1}^{3} W_{i} * T O A
$$

Where $\mathrm{W}_{\mathrm{i}}$ represents the weight of various indicators, TOA represents a different type of adaptation index.

According to the research and collation of Professor Pineda (2019), we obtained the relationship between the comprehensive index of adaptation to climate change and the type of adaptation to climate change and the state of the system (see Table 4).

Table 4. General system conditions as a function of the value of CCAI.

\begin{tabular}{lcc}
\hline CCAI Range & System status & Type of adaptation \\
\hline CCAI $\leq 0.33$ & High vulnerability & Reactive adaptation \\
$0.33<C C A I \leq 0.66$ & Intermediate vulnerability & Anticipatory adaptation \\
CCAI $\leq 1$ & Low vulnerability & Planned adaptation \\
\hline
\end{tabular}

The study of adaptability in China begins with the understanding of vulnerability, so the study of adaptability to China's energy sector cannot be separated from vulnerability. Table 4 shows the relationship between the indicator results and the adaptation type and the system state, where the index value is low when the vulnerability is high, and the index value is high when the vulnerability is low. Therefore, we can say that we pursue planned adaptation, because in this type of adaptation, not only the value of CCAI is higher, but also the value of vulnerability is lower.

\section{Results}

In order to understand the results, a classification index for each adaptation is first given: a reactivity adaptation index, an anticipatory adaptation index, and a planned adaptation index. And then the comprehensive index is analyzed.

\subsection{Reactive adaptation index}

This index (Thermal Generation /Total Generation) can be used to evaluate the substitution of thermal energy for hydraulic energy. When this index is increased, the hydraulic energy used for power generation is reduced. By producing thermal energy, more carbon dioxide is emitted, but the system vulnerability can be prevented from increasing. The relationship between this indicator and adaptation to climate change is therefore positive when the data are standardized (Abraham 2019). So the formula defined in equation (1) was used. 


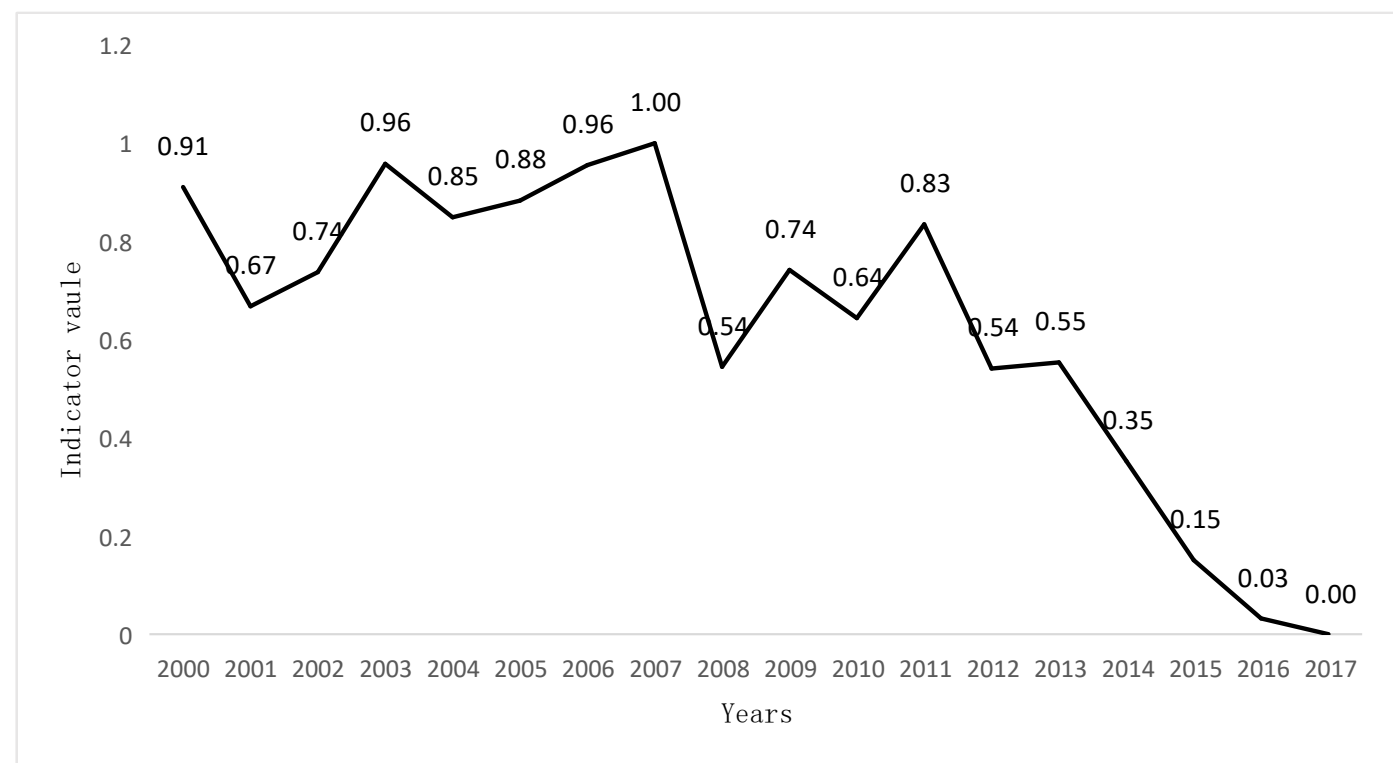

Fig 1. Behavior of reactive adaptation in the energy sector of China for 2000-2017.

In 2007, China's hydro-power development was booming, showing a vigorous scene, especially the successful closure of Xiluodu Hydro-power Station on the Jinsha River, indicates that China's hydro-power development has started a new journey. By the end of 2007, the total installed capacity of hydropower in China reached 145 million kilowatts, accounting for about $20.3 \%$ of the total capacity, an increase of $11.49 \%$ over the same period last year, which is consistent with the decline of thermal power generation in 2007-2008 shown in Fig. 1. In 2008, the natural disaster in China was very serious. In the south of China, 20 provinces (autonomous regions and municipalities directly under the central government) were affected by the severe cold rain, snow and freezing disaster, causing serious damage to water conservancy facilities. The earthquake disaster in Wenchuan, Sichuan Province, has resulted in the damage of a large number of reservoirs and hydro-power stations in 8 provinces (municipalities directly under the Central Government). This is also consistent with the increased reactivity adaptation behavior after 2008. In December 2009, the world climate conference was held in Copenhagen. Representatives from 192 countries discussed the global emission reduction agreement from 2012 to 2020. Since then, countries have begun to gradually control greenhouse gas emissions, including China. After 2011, the thermal power generation started to decline significantly, so the reactive adaptation index of energy sector in China gradually decreased, indicating that energy sector is also in the process of adapting to climate change.

\subsection{Anticipatory adaptation index}

When standardizing the data, the gap between the total power production and the total power consumption has a positive relationship with adaptation to climate change, so the formula defined in equation (1) was used.

Table 5. Hydro-power stations put into operation in China.

\begin{tabular}{lccc}
\hline $\begin{array}{l}\text { Name of hydro-power } \\
\text { station }\end{array}$ & $\begin{array}{c}\text { Time of } \\
\text { completion }\end{array}$ & $\begin{array}{c}\text { Installed } \\
\text { capacity (MV) }\end{array}$ & $\begin{array}{c}\text { Annual energy } \\
\text { output }\end{array}$ \\
\hline Longtan Dam & 2007 & 6426 & 18.7 \\
Three Gorges Dam & 2008 & 22500 & 98.8 \\
Laxiwa hydro-power & 2010 & 4200 & 10.2 \\
station & 2010 & 4200 & 19 \\
Xiaowan Dam & 2014 & 3600 & 17 \\
Jinping I & & & \\
\hline
\end{tabular}




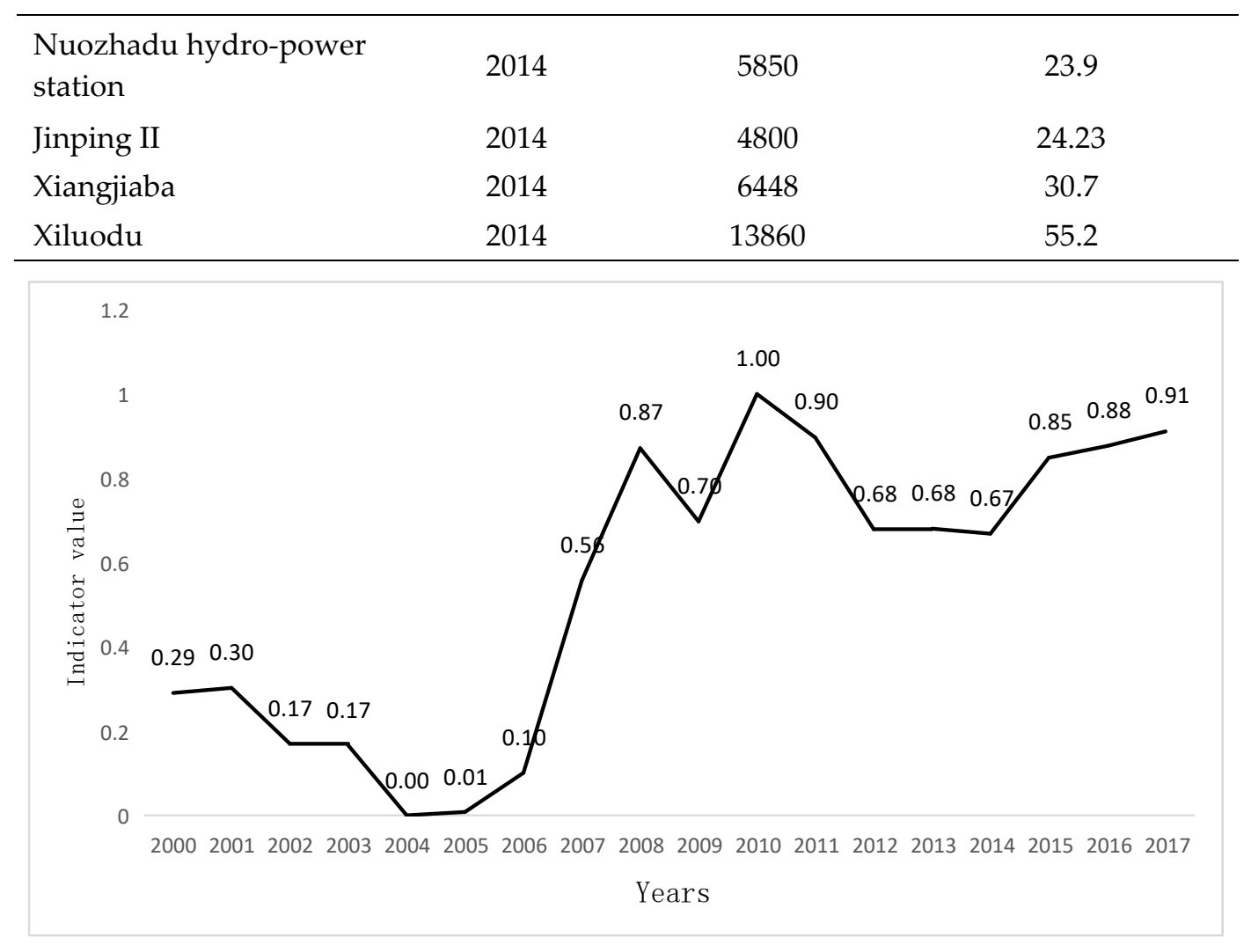

Fig 2. Behavior of anticipatory adaptation in the energy sector of China for 2000-2017.

From the raw data, the amount of electricity generated during this period is in excess of the demand, which is a good trend for the anticipatory adaptation. Moreover, by comparing the time of completion of the hydro-power station in Table 5 and the year of growth in the anticipatory adaptation index in Fig. 2, it was found that the time of the two was substantially consistent. It is indicated that the construction of the hydro-power station is in a certain degree beneficial to the anticipatory adaptation. Conversely, the good trends in the anticipatory adaptation are mainly due to construction of power plants, hydro-power stations and expansion of installed capacity of reservoirs and dams by predicting the impact of climate change.

\subsection{Planned adaptation index}

Planned adaptation consists of three variables: climate assistance funds for the energy sector in the field of adaptation, energy law in the context of climate change, and the percentage of total renewable energy power generation installations.

First, the data on climate aid funding for the energy sector in the adaptation area are mainly derived from OECD statistics on climate-related financing for development. By analyzing the proportion of energy sector in China in the funds used to adapt to climate change, we can measure the planned adaptation behavior of energy sector.

Secondly, the energy law in the context of climate change is measured according to the degree of perfection of renewable energy laws. At present, there are three levels. Until 2005, there were few specialized laws on renewable energy, even if there were regulations and policies for individual industries and regions. The adoption of the "Renewable Energy Law" in 2005 marks the existence of specialized laws on renewable energy in China, but there are no corresponding administrative regulations (corresponding government regulations, local regulations, etc). In 2013, the State Council issued "Some opinions of the State Council on promoting the healthy Development of Photovoltaic Industry", and so China has corresponding administrative regulations. Appendix 1 lists the relevant legal documents and hierarchical divisions. 
Finally, the percentage of renewable energy power generation installed is increasing year by year from the original data. Among them, for China, the largest installed capacity is hydro-power. China has 678 million kilowatts of hydro-power resources and 5.92 trillion kilowatt hours of annual electricity generation, ranking first in the world and has a bright development prospect. The famous hydro-power stations in China include Three Gorges Hydro-power Station, Gezhouba Hydro-power Station and Xiaolangdi Hydro-power Station. Among them, the Three Gorges Hydro-power Station is the largest hydro-power station in the world, with an installed capacity of 22.5 million kilowatts.

When the data are standardized, the three indices show a positive relationship to adaptation to climate change, so the formula defined in equation (1) is also used. The standardized data are weighted summarized (see 2.5) and the planned adaptation index is obtained (Fig. 3).

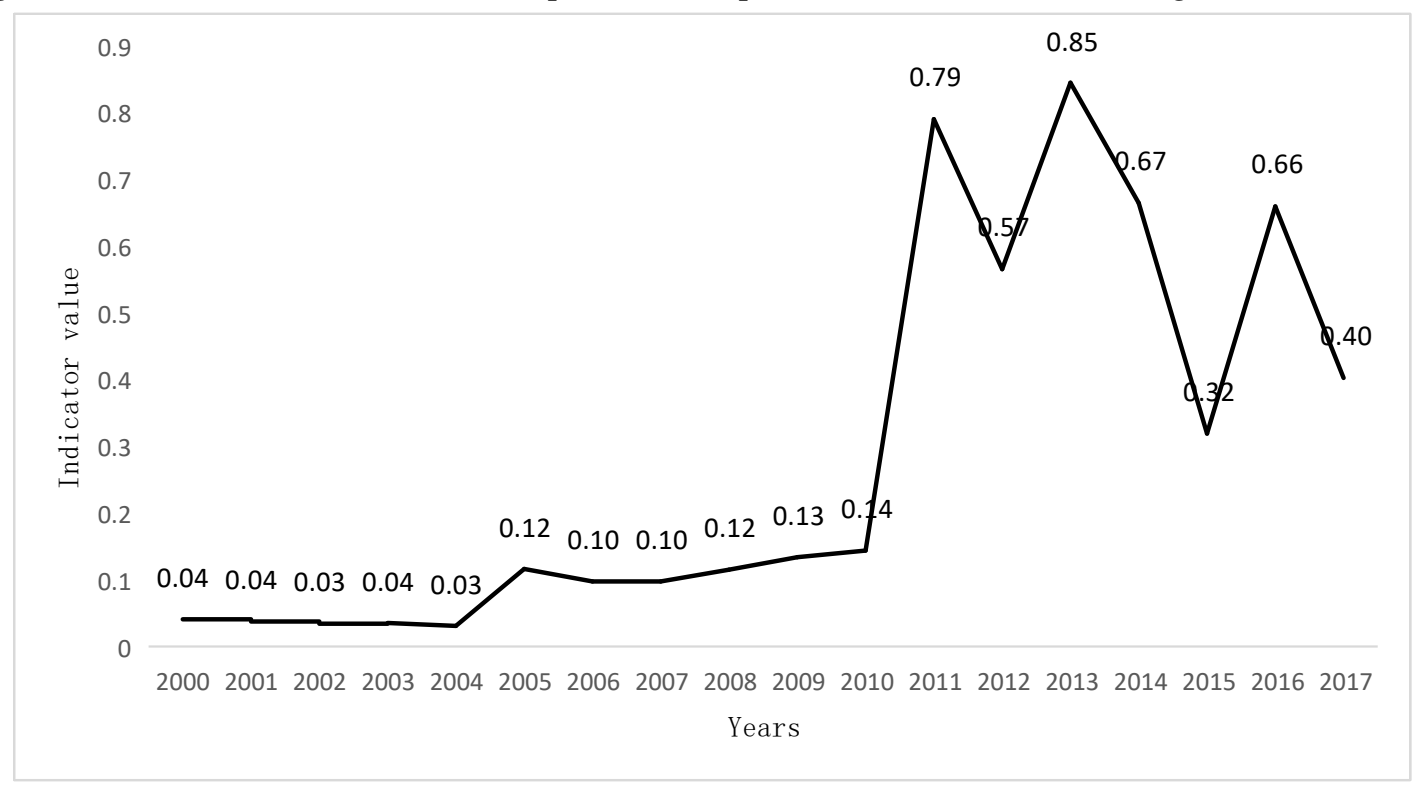

Fig 3. Behavior of planned adaptation in the energy sector of China for 2000-2017.

It is clear from Fig. 3 that there has been a small ladder jump in the planned adaptation index after 2005, mainly due to the adoption of the "Renewable Energy Law" in China. After 2010, the planned adaptation index increased significantly, which is the result of the comprehensive effect of three kinds of data. However, from the perspective of weight and raw data, climate assistance funds to the energy sector in the field of adaptation have played a relatively large role, as evidenced by the sharp drop in the 2015.

\subsection{Aggregate adaptation to climate change index}

Based on the formula defined in equation (3), the sum of the reactive, anticipatory, and planned adaptation indices results in the CCAI for the energy sector of China in the 2000-2017 period.

Table 6. Behavior of Climate Change Adaptation Index in the energy sector of China for 2000-2017.

\begin{tabular}{ccll}
\hline Year & CCAI & Types of adaptation & System status \\
\hline 2000 & 0.128241207 & Reactive adaptation & High vulnerability \\
2001 & 0.109756849 & Reactive adaptation & High vulnerability \\
2002 & 0.097855133 & Reactive adaptation & High vulnerability \\
2003 & 0.113801378 & Reactive adaptation & High vulnerability \\
2004 & 0.084958774 & Reactive adaptation & High vulnerability \\
2005 & 0.158587811 & Reactive adaptation & High vulnerability \\
2006 & 0.158054886 & Reactive adaptation & High vulnerability \\
\hline
\end{tabular}




\begin{tabular}{lccc}
\hline 2007 & 0.209545093 & Reactive adaptation & High vulnerability \\
2008 & 0.225477924 & Reactive adaptation & High vulnerability \\
2009 & 0.236337217 & Reactive adaptation & High vulnerability \\
2010 & 0.26968142 & Reactive adaptation & High vulnerability \\
2011 & 0.805302867 & Planned adaptation & Low vulnerability \\
2012 & 0.576272477 & Anticipatory adaptation & Intermediate vulnerability \\
2013 & 0.80772862 & Planned adaptation & Low vulnerability \\
2014 & 0.643681047 & Anticipatory adaptation & Intermediate vulnerability \\
2015 & 0.363720145 & Anticipatory adaptation & Intermediate vulnerability \\
2016 & 0.639065936 & Anticipatory adaptation & Intermediate vulnerability \\
2017 & 0.428508865 & Anticipatory adaptation & Intermediate vulnerability \\
\hline
\end{tabular}

The data in Table 6 show the system status and adaptation types from 2000 to 2017. It can be seen that the reactive adaptation has continued into 2010, indicating the high vulnerability of the energy sector during this period. Between 2011 and 2017, progress was made in active adaptation. Overall, it can be seen that progress has been made in anticipatory adaptation, indicating that the construction of reservoirs, hydro-power stations and power plants in China has enhanced adaptability and mitigated the effects of climate. However, there has not been a real leap forward in planned adaptation, and although a brief leap forward in planned adaptation was achieved in 2011 and 2013, this is not stable and is related to the sudden increase in climate assistance to the energy sector in the area of adaptation that year.

\section{Discussion}

From the current research results, the energy sector of China has developed from reactive adaptation to active adaptation. However, this does not mean that the state of the system will improve indefinitely, either because of the limitations of the selection of indicators or the impact of special data, such as climate assistance funds for the energy sector in the field of adaptation, or because the method used in weight calculation is single. Although entropy method has high reliability and accuracy, it lacks horizontal comparison among various indexes.

The current warming trend cannot be stopped or reversed, but it can be slowed down, giving the biological system and human society more time to adapt. In addressing climate change, China attaches equal importance to both mitigation and adaptation. Mitigation is a relatively long-term and arduous task, while adaptation is more realistic and urgent. Mitigation and adaptation must be taken into account, coordinated and balanced, with equal emphasis. At present, mitigation and adaptation are difficult to separate, and they are two organic components of climate change (2008). Some scholars believe that long-term adaptation strategies can be regarded as mitigation, for example, the law on renewable energy is not only to adapt to climate change, but also has an impact on mitigation. However, the issue of adaptation is a budding one. At present, the measures and quantification of adaptation to climate change are still limited. So far, the tools used to assess adaptation are vague and controversial in many cases, which need further exploration. More importantly, there is not much research on adaptation to climate change in the energy sector of China.

Therefore, this work is to further explore and try to balance this situation by establishing a comprehensive index to assess the progress of energy sector of China in adapting to climate change. The ideal of the index is planned adaptive behavior, and it is hoped that the subsequent research can further constitute a monitoring tool, so that the government can take action to reduce the vulnerability of the system and transform the government's intervention into improving the adaptability. Unlike most tools that assess climate change adaptation from impact measurement methods and focus on future climate prediction, this work provides tools not only to assess the overall state of the system through the value of CCAI, but also to help determine what happens under each 
subsystem. This enables governments to intervene in each of the adaptation indicators that constitute the climate change adaptation index. For example, the current government uses the carbon emission trading right mechanism and other market-based means to achieve emission reduction targets, continues to increase water conservancy construction, and actively improves energy-related laws. All these actions are to improve the adaptability through government intervention. After that, the Chinese government should determine investment policies and priorities based on its own strengths and the realities of the energy sector, and make better decisions to make energy sector of China less vulnerable to climate change (Abraham 2019).

\section{Conclusions}

The results of reactive adaptation show that after the vigorous development of hydropower in China and took the initiative to assume the responsibility of a great country to reduce emissions, thermal power generation is significantly reduced and replaced by other power generation modes. This will not only reduce more greenhouse gases, but also be cheaper in the long run.

The results of anticipatory adaptation show that China maintains a good trend of anticipatory adaptation after 2007 by predicting the influence of climate change, building power plants, hydro-power stations and expanding the installed capacity of reservoirs and dams.

According to the planned adaptation behavior, the adoption of the Renewable Energy Law in 2005 has improved the planned adaptation behavior. After 2010, the climate assistance funds to the energy sector in the field of adaptation began to play a role, which to a great extent affected the planned adaptation behavior.

Based on the overall results of CCAI, a reactive adaptation scheme is proposed to assess the progress of climate change adaptation in energy sector of China from 2000 to 2010. In 2011 and 2013, due to the sudden increase of climate assistance funds to the energy sector in the field of adaptation, a short leap of planned adaptation was achieved, which greatly reduced the vulnerability of the system, but this situation was not stable. Therefore, on the whole, after 2011, there has been an anticipatory adaptation scenario, that is, vulnerability is average. Therefore, at present, the adaptability to climate change of energy sector in China has increased, from reactive adaptation with high system vulnerability to anticipatory adaptation with average vulnerability, and the sector is laying the foundation for planned adaptation scenario.

Acknowledgments: First of all, I would like to thank my supervisor Rong Kang and the teacher Beibei Shi for their help, and secondly, I am very grateful to the Professor Pineda for his guidance and help in the process of my writing. His article inspired me a lot, and the communication with him answered a lot of my questions. Finally, I would like to thank the National Social Science Fund project "National Climate change negotiation difficulties and China's active participation in the negotiations" for the financial help.

\section{References}

Abraham Allec Londoño Pineda,Oscar Alonso Vélez Rojas (Oscar),M.P. Jonathan,S.B. Sujitha. 2019.Evaluation of climate change adaptation in the energy generation sector in Colombia via a composite index - A monitoring tool for government policies and actions. Journal of Environmental Management.250.https://doi.org/10.1016/j.jenvman.2019.109453.

Beermann, M. 2011. Linking corporate climate adaptation strategies with resilience thinking. J. Clean. Prod. 19 (8), 836-842. https://doi.org/10.1016/j.jclepro.2010.10. 017.

Busch, T. 2011. Organizational adaptation to disruptions in the natural environment: the case of climate change. Scand. J. Manag. 27 (4), 389-404. https://doi.org/10.1016/j. scaman.2010.12.010.

Chen Jue. 2011. Study on Energy Law-making related to Climate change . Available online: http://kns.cnki.net/kns/detail/detail.aspx?FileName=1011050639.nh\&DbName=CMFD2011.

Ding Ding, Liu Hengwei, Dai Dongbao. 2015. A preliminary study on the framework of climate risk assessment and management system in China's energy sector.Energy of China.37,17-21.https://doi.org/10.3969/j.issn.1003-2355.2015.05.002.

IPCC, 2001. Climate Change 2001: Impacts, Adaptations and Vulnerability. Cambridge University Press, Cambridge, U.K., pp. 1-1005. 
IPCC, 2007. Climate Change 2007: Summary Report. Contribution from Work Groups I, II, and III to the Fourth Assessment Report on Climate Change from the. Inter Government Expert Group. IPCC, pp. 1-863.

IPCC, 2014. Climate Change 2014: Impacts, Adaptation, and Vulnerability: SUMMARY for POLICYMAKERS. IPCC, pp. 1-34.

Ke Jian. 2015. Legal Promotion of Renewable Energy Development in the Background of Global Climate Change: Reflecting and Reshaping Renewable Energy Law of China.Journal of Political Science and Law.04,75-83.Available online:http://kns.cnki.net/kcms/detail/detail.aspx?FileName=ZFLC201504009\&DbName=CJFQ2015.

Liu Congcong. 2017. Energy Law Reform and system Innovation under the background of Climate change. Legal System and Society.05,39-40.https://doi.org/10.19387/j.cnki.1009-0592.2017.02.152.

The state council information office of China. 2008. Policies and actions to address climate change in China. Available online:http://www.china.com.cn/policy/qhbh/node_7055577.htm.

Wang Juan. 2016. Research of Renewable Energy Legal System in the Context of Climate Change. Available online:http://kns.cnki.net/kns/detail/detail.aspx?FileName=1016148128.nh\&DbName=CMFD2016.

Wang Bing. 2016. Risk Assessment Methods for Renewable Energy Systems and Their Applications. Beijing Institute of Technology. Available online:https://kns.cnki.net/KCMS/detail/detail.aspx?dbcode=CDFD\&dbname=CDFDLAST2017\&filename= 1016710637.nh\&v=MDI0OTBoMVQzcVRyV00xRnJDVVI3cWZadVJ1Rnk3bVdyek9WRjI2R0xTNUh0Z1BxS kViUElSOGVYMUx1eFITN0Q=.

Yang Lizhi, Zhang Ren, Wu Yancheng, Ge Shanshan, Liu Jun. 2016. Safety Risk analysis and Assessment of Climate Change on China's Maritime Energy Channel. Journal of Applied Sciences,34(06):713-723. https://doi.org/10.3969/j.issn.0255-8297.2016.06.007.

Zhai Ruiyan. 2018. Research on China's legislation on Climate change Energy---taking the Paris Agreement as a breakthrough point. Available online:http://kns.cnki.net/kns/detail/detail.aspx?FileName=1018228135.nh\&DbName=CMFD2019. 